\title{
AÇÕES DE DESTITUIÇÃO DO PODER FAMILIAR EM PROCESSOS DE ADOÇÃO NO RIO DE JANEIRO: VALORES MORAIS E PRÁTI- CAS LEGAIS
}

CASES OF TERMINATION OF PARENTAL AUTHORITY"IN RIO DE JANEIRO: MORAL VALUES AND LEGAL PRACTICES.

\section{Alessandra de Andrade Rinaldi ${ }^{1}$}

RECEBIDO EM: 16/06/2020 | ACEITO EM: 25/06/2020

DOI: $10.5902 / 2317175847247$

\section{RESUMO}

O objetivo do artigo é compreender como são conduzidas as "ações de destituição de poder familiar" (DPF) de crianças e jovens em processo de adoção. Interessa também analisar como são julgados esses processos quando as "genitoras" cumprem pena privativa de liberdade em instituições prisionais. Propomos análise comparativa em ações cujas mães de nascimento não são privadas de liberdade, buscando apreender se há alguma especificidade nas situações que envolvam mulheres presas e sua prole. Almejamos entender, a partir da análise de quarenta e nove processos, quais são os valores e saberes produzidos pela equipe técnica das Varas da Infância, da Juventude e do Idoso (psicólogos e assistentes sociais) em seus pareceres técnicos para convencer juízes sobre a viabilidade de uma DPF. Com o intuito de materializar esses objetivos, acreditamos que, apesar de haver variação de conteúdos nos "autos" coletados, a análise de três dessas ações nos possibilita inferir como diferentes práticas de justiça em âmbito da Infância e da Juventude estão organizadas. Acreditamos que há uma estreita relação entre pressupostos morais familiares, suportados nas relações de gêneros, assim como em concepções sobre garantias de direitos e em visões científicas sobre a pessoa nas práticas de justiça em questão.

Palavras-chave: Adoção; Parentesco; Vínculos familiares; Valores morais e Práticas legais.

\footnotetext{
1 Professora Adjunta em Antropologia Social -UFRRJ. Possui graduação em Ciências Sociais pela Universidade Federal de Juiz de Fora (1994), mestrado em Antropologia pela Universidade Federal Fluminense (1997) e doutorado em Saúde Coletiva pela Úniversidade do Estado do Rio de Janeiro (2004) e Pós-doutorado em Antropologia Social pelo PPGAS/MN-UFRJ. Desenvolve pesquisas sobre gênero, violência, família e parentesco. Desde o ano de 2010 tem pesquisado a filiação adotiva.
} 
AÇÕES DE DESTITUIÇÃO DO PODER FAMILIAR EM PROCESSOS DE ADOÇÃO NO RIO DE JANEIRO: VALORES MORAIS E PRÁTICAS LEGAIS

\section{ABSTRACT}

The purpose of this paper is to understand how the "cases of termination of parental authority" over children and young adults in the process of adoption are tried. It also analyzes how these cases are tried when "mothers" are serving time in prison. To achieve these objectives, we propose a comparative research on cases including "parents" that are not serving time in prison, by trying to determine if there is any specificity in situations involving female convicts and their children.

Therefore, we aim to understand the values and knowledges produced by the technical staff of the Juvenile and Elderly Courts, including psychologists and social workers, in their technical opinions to convince judges on the feasibility of such termination of parental authority. We aim to understand from the analysis of forty-seven processes what are the values and knowledge produced by the technical staff of the Child, Youth and Elderly Courts (psychologists and social workers) in their technical opinions to convince judges about the feasibility of this DPF. In order to materialize these objectives, we believe that, although there is a variation of content in the collected records, the analysis of three of these actions allows us to infer how different justice practices in the scope of Childhood and Youth are organized through a close relationship between family moral presuppositions supported in gender relations, as well as in the conceptions about guarantees of rights and in scientific conceptions about the person

Keywords: Adoption; kinship; Family ties; Moral values and Legal practices.

\section{Introdução}

O presente artigo está ligado ao projeto “Laços desfeitos, vínculos construídos", cujo propósito é compreender os significados da filiação adotiva para os integrantes do Direito, que militam na área da adoção na comarca do Rio de Janeiro ${ }^{3}$. O objetivo é compreender como são conduzidas as "ações de destituição de poder familiar" (DPF) de crianças e jovens em processo de adoção. Interessa também analisar como são julgados esses processos quando as "genitoras" cumprem pena privativa de liberdade em instituições prisionais. Propomos análise comparativa em ações cujas mães de nascimento não são privadas de liberdade, buscando apreender se há alguma especificidade nas situações que envolvam mulheres presas e sua prole.

Almejamos entender, a partir da análise de quarenta e nove processos, quais são os valores e saberes produzidos pela equipe técnica das Varas da Infância, da Juventude e do Idoso (psicólogos e assistentes sociais) em seus pareceres técnicos para convencer juízes sobre a viabilidade de uma DPF. Com o intuito de materializar esses objetivos, acreditamos que, apesar de haver variação de conteúdos nos "autos" coletados, a análise de três dessas ações nos possibilita inferir como diferentes práticas de justiça em âmbito da Infância e da Juventude estão organizadas. Acreditamos que nesses documentos há uma estreita relação entre pressupostos morais familiares suportados nas relações de gêneros, assim como em concepções sobre garantias de direitos e em visões científicas sobre a pessoa.

3 Essa pesquisa é coordenada por Alessandra de Andrade Rinaldi e apoiada pelo CNPO (bolsa de produtividade) e pela FAPERJ (APQ1 E-26/010.002184/2015). Além do apoio dado pelas agências de fomento esta foi aprovada pelo Comitê de Ética da UFRRJ (protocolo no 601/2015) e pela Escola de Gestão Penitenciária CI SEAP (EP n०072). Como parte desse projeto, há a dissertação de mestrado sobre destituição de poder familiar de mulheres em situação prisional, desenvolvida por Letícia Mara Sales (2019) em âmbito do PPGCS-UFRRJ. 
À luz de Muzzopapa e Villalta (2011) compreendemos esses "autos" processuais como peças - resultantes do fluxo da burocracia das práticas da justiça da infância e da juventude - produzidas por diversos atores como advogados, promotores de justiça, psicólogos, assistentes sociais, juízes, pais adotivos, famílias "doadoras" (cujos filhos serão adotados). Levamos em conta, no entanto, que não só os profissionais são peças fundamentais nessas ações: "pretendentes à adoção", pais adotivos, assim como pais de nascimento também se manifestam acerca das situações pelas quais estão sendo avaliados.

Por essa razão, partimos do pressuposto de que as pessoas envolvidas nesse fluxo, ao produzirem seus relatórios, ao tomarem suas decisões ao longo dos caminhos processuais, levam em conta as versões morais contidas nos depoimentos dos "pretendentes à adoção" e/ou dos processados (genitores). Significa dizer que um documento dessa natureza não se sustenta exclusivamente por "fatos legais", mas também por "sensibilidades" produzidas à luz de moralidades relativas aos gêneros, às noções sobre famílias, afetos, projetos parentais, perturbação e noções sobre a pessoa humana e seus direitos.

Partindo dessas considerações, pesquisamos "ações de destituição do poder familiar" conectadas aos processos de adoção ${ }^{4}$, assim como aquelas movidas sem vinculação a esses requerimentos. Dessa forma, cabe considerar que um processo de adoção é um procedimento jurídico que transfere todos os direitos dos pais biológicos para uma família substituta, inclusive a aquisição do sobrenome dos adotantes (Bittencourt, 2000; Rinaldi, 2014; 2017). Para tanto, é necessário que a família de nascimento seja destituída de seu poder familiar (DPF).

A propositura de uma ação de "destituição do poder familiar" (DPF) é de competência do Ministério Público, mas pode ser movida por um parente do infante ou do jovem, quando se entender, segundo o art. 1637 do Código Civil de 2002, que um pai ou uma mãe "abusou de sua autoridade ou faltou com os deveres a eles inerentes" 5 . Nesse caso, competirá ao Juiz da área da Infância e da Juventude decidir, em caráter "liminar ou incidentalmente", o destino da criança ou do jovem envolvido, que ficará sob a tutela do Estado ou sob a guarda de "pessoa idônea" até a decisão final do magistrado.

No Brasil, no entanto, é comum que uma decisão sobre a DPF, ação requerida, em sua maioria, pelo Ministério Público, seja feita por meio da suspensão "liminar" do poder familiar, até que a decisão sobre a destituição seja proferida. Nessas situações a criança pode ser separada de grupo de nascimento, por meio da suspensão, até que a decisão final seja dada. Isso não impede que seja conduzida a outra família que moverá, em concomitância, um processo de adoção para filiá-la.

Isso, de acordo com os adotantes, gera insegurança jurídica materializada pelo medo de perder seus filhos para os genitores, posto que essas crianças

4 Segundo Rossato (2012), trata-se de pedido "que somente será analisado se o relativo à destituição do poder familiar puder ser acolhido" (2012.p. 437). Nestes casos a destituição, requerida, em sua maioria pelo Ministério Público, é realizada em "caráter liminar". Tratam-se de situações nas quais o processo de destituição de poder familiar ocorre simultaneamente com o processo de adoção, para que o procedimento ocorra de maneira rápida e evite trâmites burocráticos demorados.

5 As razões que levam à "suspensão" ou à destituição do poder familiar estão previstas tanto nos artigos 1637 e 1638 do Código Civil de 2002, quanto no artigo 24 do Estatuto da Criança e do Adolescente (ECA). 
podem ser transferidas para novas famílias sem a ruptura definitiva com os pais de nascimento. Além disso, tal situação enseja constrangimentos em espaços de socialização, como escolas, clínicas pediátricas onde os nomes de origem dos fiIhos são citados constantemente levando, assim, à ideia de que a "verdade biológica" está imposta sobrepondo-se à lei/da nomeação (PINA CABRAL, 2005).

Por meio desse percurso analítico, buscamos entender como e por que um pai e/ou uma mãe são compreendidos como inaptos ao exercício da "função parental". Dito de outra forma, a intenção é captar como práticas legais e sanções morais sobre "genitores" e suas proles se materializam nesses documentos.

\section{Metodologia e a seleção dos processos}

Até recentemente existiam três varas no Rio de Janeiro: Vara de Infância Juventude e do Idoso da Comarca da Capital (VIJI), Vara da Infância da Juventude e do Idoso ( $\left.1^{\circ} \mathrm{VIJI}\right)$ - regional de Madureira - e Vara da Infância da Juventude e do Idoso ( $\left.2^{\circ} \mathrm{VIJI}\right)$ - regional de Santa Cruz. Já atualmente existem quatro: $1^{a}$ Vara da Infância da Juventude e do Idoso da Comarca da Capital, $2^{\text {a }}$ Vara da Infância da Juventude e do Idoso da Comarca da Capital, $3^{\text {a }}$ Vara da Infância da Juventude e do Idoso - regional de Madureira - e $4^{\text {a }}$ Vara da Infância da Juventude e do Idoso - regional de Campo Grande ${ }^{6}$.

Para o presente artigo analisamos processos da extinta regional de Santa Cruz, atual regional de Campo Grande, da regional de Madureira e da Vara da Comarca da Capital, antes e após sua subdivisão. No entanto, a Vara da Comarca da Capital acabou sendo subvalorizada, posto que no começo de 2010 houve uma resposta negativa sobre a possibilidade dessa pesquisa. Só tempos depois, em 2018, foi oportunamente liberado o acesso ao cartório da Comarca da Capital'.

Durante esse percurso coletamos quarenta e nove processos de "destituição de poder familiar". Dentre tais documentos, vinte e cinco tramitaram na $2^{\text {a }}$ Vara da Infância da Juventude e do Idoso regional de Madureira e vinte e um na $4^{a}$ Vara da Infância da Juventude e do Idoso regional de Campo Grande, bem como três na $1^{\text {a }}$ Vara da Infância da Juventude e do Idoso ${ }^{8}$. Dentre esses, vinte e nove estão sentenciados e vinte ainda estão em andamento processual. Quanto à propositura da ação, doze são ações privadas e as outras trinta e sete são movidas pelo Ministério Público (MP). No tocante ao perfil socioeconômico dos sujeitos da ação, pudemos identificar que os "genitores/réus" são majoritariamente de famílias populares urbanas 9

6 Vara criada há pouco tempo, abrange os processos que tramitaram na extinta Vara da Infância da Juventude e do Idoso, regional de Santa Cruz.

7 Esse trabalho foi realizado com o apoio de uma equipe pesquisadoras. Dentre elas estavam três alunas de mestrado do Programa de Pós-Graduação em Ciências Sociais da Universidade Federal Rural do Rio de Janeiro; uma mestranda em Direito Constitucional da Universidade Federal Fluminense (cinco alunas de cursos de graduação da UFRRJ. Quatro dessas últimas atuaram como bolsistas de iniciação científica, orientadas por mim e apoiadas pelas agências de fomento CNPQ e FAPERJ, e duas alunas usaram parte da pesquisa para realizar suas monografias de curso de graduação em Ciências Sociais da UFRRJ. Essa equipe atuou em distintos períodos entre fevereiro de 2016 a fevereiro de 2019.

8 Em razão do segredo de justiça que esses documentos requerem, optamos por não citar os números dos processos.

9 Segundo Couto (2005), “a categoria famílias populares urbanas. [...] se refere de forma genérica àqueles 
Em termos metodológicos, entendemos os processos de adoção e as ações de "destituição de poder familiar" tal como proposto por (Vianna 2002), isto é, como um conjunto de relatos convertidos em "depoimentos", escritos por um mecanismo de controle burocrático e de construção de afirmação de autoridade fundamentais para a produção de uma decisão judicial ${ }^{10}$. Por conseguinte, entendemos um "auto" como resultado de um confronto de posições de autoridade entre os que depõem e os que são responsáveis por "traduzir" as falas em termos da universalidade jurídica. Dessa forma, uma vez demarcado o poder desses últimos, o que se tem como resultado e/ou depoimento é algo que foi produzido sob condições de constrangimento11.

Levamos em conta que não só os profissionais que compõem os "autos" possuem "voz" ao longo do fluxo processual, os processados também se manifestam acerca das situações pelas quais estão sendo avaliados. Por essa razão, partimos do pressuposto de que as pessoas envolvidas nesse fluxo ao produzirem seus relatórios, ao tomarem suas decisões e ao conduzirem os caminhos processuais levam em conta as versões morais contidas nos depoimentos dos processados.

Acreditamos, portanto, que os responsáveis por acolher, avaliar, analisar e julgar esses pais e mães não produzem suas considerações sobre o fato legal, exclusivamente por um olhar disciplinante e normativo em face dos processados. Cremos que as práticas legais, nesse caso, são invadidas e alargadas pelas vozes de pessoas alocadas às margens do Estado ${ }^{12}$ (Das e Poole, 2004) em razão da desconformidade em relação aos dispositivos legais que regulam a família, a infância e a juventude.

\subsection{A escolha dos processos}

Nessa pesquisa, ponderamos que nos documentos aparecem múltiplas construções e interpretações sobre o que leva uma pessoa a não poder mais permanecer no lugar de pai ou de mãe. Consideramos, portanto, que há múltiplas vozes concorrentes na produção de um discurso de verdade (Foucault, 2001) sobre quem pode ou não compor uma família. Há profissionais responsáveis por esquadrinhar os "acusados" com o intuito de avaliar sua lucidez, sua moral e seu direito, atestando ou não a possibilidade de continuar a serem pais ou mães. Membros do conselho tutelar, psiquiatras, promotores de justiça, defensores públicos, juízes da Infância e da Juventude, psicólogos e assistentes sociais, que atuam nas Varas da Infância e da Juventude e/ou em instituições de acolhimento, em prisões e/ou em maternidades são convocados a comentar o "desempe-

\footnotetext{
que são destituídos do que, na nossa sociedade, confere poder, riqueza e prestígio" (2006,p. 198).

10 VIANNA, Op. Cit, p. 94.

11 Idem.

12 Das e Poole (2004) consideram "margens do Estado": "El primer enfoque dio prioridad a la idea de margen como periferia em donde están contenidas aquellas personas que se consideran insuficientemente socializadas en los marcos de la ley" [..]Un segundo enfoque relacionado con el concepto de margen [...] gira en torno a los temas de legibilidad e ilegibilidad Reconocemos que las prácticas de relevamiento documental y estadísticodel estado están al servicio de la consolidación del control estatal sobre lossujetos, las poblaciones, los territorios y las vidas.[...] Un tercer enfoque se concentra en el margen como el espacio entre loscuerpos, la ley y la disciplina".(2004, p.24-25)
} 
nho" desses sujeitos em vista de serem destituídos de suas "funções parentais".

A partir dessa perspectiva, escolhemos para o presente artigo analisar comparativamente três ações. Duas delas estão contidas em processos de adoção e foram movidas contra ambos os "genitores"; outra foi aberta contra uma mãe, cujos filhos não possuíam registro paterno. A ideia foi apreender como nesses "autos" são construídos padrões de moralidades, "verdades científico-periciais" e/ou discursos de "direitos" sobre os sujeitos propensos a serem destituídos.

Acreditamos que, apesar de variação de conteúdos presentes nos quarenta e nove processos, a análise dessas três ações nos possibilita inferir como diferentes práticas de justiça (Schuch, 2004) em âmbito da Infância e da Juventude estão organizadas. Como dito antes, apostamos na existência de elos entre pressupostos morais suportados nas relações de gêneros, assim como nas concepções sobre garantias de direitos e em concepções científicas sobre a pessoa.

A proposta é perceber como, em um mesmo documento, pode haver o uso concorrente dessas três ordens classificatórias para a produção sobre as razões que levam à DPF. Dessa forma, a intenção com essa escolha é analisar em que medida a conduta moral dos processados, as discussões relativas aos direitos da criança e do adolescente e ao exercício da função parental, assim como as produções médico-psiquiátricas sobre doenças mentais e condutas em face aos filhos são mesclados em tais ações.

\section{A análise dos processos escolhidos}

O primeiro processo escolhido enseja um pedido de "destituição do poder familiar" em face de Jurandir e Maria "cumulado" com um requerimento de adoção de Mariana, filha de ambos ${ }^{13}$. A ação foi proposta pelo casal Bento e Beatriz, padrinhos e guardiões consensuais de Mariana. A menina lhes foi "entregue", ainda bebê, por Maria, na época acometida por uma "depressão pós-parto", supostamente ocasionada por um divórcio do então marido. Passados alguns anos, Maria refez a vida, casou-se de novo e retornou à casa de Beatriz com o intuito de reaver Mariana. Beatriz, nesse momento, separada de Bento, recusou-se a entregar a criança, acusando Maria de tê-la "abandonado". Pudemos perceber que a discussão central do processo ruma em torno da avaliação moral da "mãe abandonante" e de um silêncio sobre a participação paterna na escolha sobre o destino de Mariana, assim como a partir de uma reflexão jurídica sobre a aplicação do "princípio do melhor interesse da criança e do adolescente".

O segundo processo foi proposto pelo Ministério Público em face de Joana ${ }^{14}$, "portadora de transtorno psiquiátrico", com manifesto "comportamento agressivo" e "delírios persecutórios". A "ré" foi denunciada por ter "exposto" seus dois filhos, Manoel, nove anos, e Pedro, cinco anos, cujos pais são "desconhecidos" "à situação de abandono, grave negligência, gravíssimo risco pessoal e social e à prática de atos contrários à moral e aos bons

13 Os nomes e alguns elementos das histórias são ficcionais para que o segredo de justiça seja resguardado. 14 Usaremos nomes fictícios com o intuito de resguardar o anonimato dos envolvidos. 
costumes" (grifo nosso). Ao longo dos "autos", Joana é descrita como uma "mãe negligente", que mantém os filhos em "cárcere privado", sem alimentá-los e sem ensiná-los hábitos básicos de higiene. Apesar da inexistência de laudo pericial, a "acusada" é moralmente classificada pelos depoentes e por profissionais envolvidos no fluxo processual como "louca". Dessa forma, a condução primordial do processo é o "diagnóstico" de loucura e a consideração sobre a possibilidade ou não de exercer a maternidade.

O terceiro processo diz respeito à "ação de destituição de poder familiar" proposta pelo Ministério Público (MP) em face dos "réus" Carolina e Evandro, genitores de Pedro, nascido no sistema prisional, na Unidade Materno Infantil (UMI) - Talavera Bruce e posteriormente encaminhado a uma instituição de acolhimento. De acordo com a inicial proposta pelo MP, o bebê nasceu sob a tutela do sistema prisional. A criança ficou sob os cuidados materno até os sete meses de idade e, ao longo desse período, foi registrado por Evandro, que o reconheceu como filho. Apesar de a ação requerer a destituição de ambos os "genitores", todas as argumentações versam sobre essa mãe "presidiária", acusada por maus tratos por "gritar e sacudir a criança com violência para forçá-lo a comer". O episódio foi comunicado ao Juizado de Direito da VIJI, que decidiu pelo encaminhamento da criança à uma instituição de acolhimento infantil. O processo ruma em torno de dois eixos: a "proteção integral" da criança, da garantia de que viveria em família, e a discussão sobre a possibilidade de que uma mulher presidiária possa ou não exercer o poder familiar.

\subsection{Duas famílias: uma criança}

O processo em questão, segundo a peça inicial proposta por defensores públicos, representantes legais do casal Bento e Beatriz, trata "[de pedido de] destituição do poder familiar c/c ação de adoção com antecipação de tutela, em face de Jurandir e Maria [e de requerimento de] [...] guarda provisória da menor Mariana, considerando que esta reside na casa dos autores desde um ano e meio [..]".

De acordo com o relatório psicossocial produzido pela equipe técnica da Vara da Infância e da Juventude, a ação diz respeito a "duas famílias que brigam pela posse de uma criança". Segundo os "autos", o casal Jurandir e Maria possuía dois filhos. No entanto, acabaram se separando, pouco depois do nascimento de Mariana, a segunda filha de ambos e objeto da ação.

Maria teve uma "depressão pós-parto" e "não tinha condições financeiras, nem psicológicas para cuidar de suas filhas quando se separou do requerido". Por esse motivo, pediu à sua irmã para que cuidasse de sua filha mais velha e à "requerente", que vem ser sua madrinha, que cuidasse de Mariana. Jurandir estava de acordo com a decisão da companheira, pois ele "não se encontrava em condições de cuidar sozinho da filha". Consta nos "autos" que ambos entendiam a situação como temporária. 
Jurandir e Maria construíram novas relações afetivas. Por essa razão, a "genitora" "quis pegar Mariana de volta". Entretanto, Beatriz, a "requerente", pediu que "a deixasse mais um pouco, pois havia se apegado a criança". Assim, Mariana vivia entre três casas: a de Maria, a de Jurandir e a da "requerente". Segundo relatório psicossocial, "foi assim por anos, até que o genitor quis que a filha ficasse vivendo mais em sua casa do que na casa da requerente. Esta não aceitou a decisão da genitora e entrou com o pedido de adoção".

Maria afirma que ao longo desse processo não foi ouvida e que deseja reaver a guarda da filha. Sobre esse pleito, Jurandir se manifesta e diz que "Maria [é] uma boa mãe, que jamais abandonou a filha, assim como ele também não" (grifo nosso). Sobre o pedido de adoção, disse sentir-se enganado pela "requerente", "pois permitiu que ela detivesse a guarda de sua filha pensando que se tratava apenas de facilitar assuntos escolares, por exemplo". Só tomou ciência de que se tratava de uma ação de adoção, quando foi assinar a documentação e nesse ato se opôs ao pleito, dizendo que consentia apenas com a guarda, mas não com a adoção.

O casal processado, ao falar de seus atos, busca positivar suas decisões por meio de um cálculo de repercussão (Vianna, 2002). Maria, por exemplo, procura realçar para os agentes da justiça que não "abandonou" a filha, mas antes a deixou sob os cuidados da madrinha, provisoriamente. À luz de considerações feitas por (Vianna 2002), é possível apreender que a noção de "abandono" é passível de contestações e de reordenações de significados, dependendo das configurações morais das pessoas a quem este termo se refere.

Não só os processados procuram a positivação de seus atos, mas também seus representantes legais caminham em mesma direção. A defensora pública, representante legal de Maria, ao requerer a improcedência da ação, afirma que:

"[a requerida] foi acometida de depressão pós-parto e que [Jurandir] separou-se dela em seguida, deixando a mesma e a menor desamparadas". Esclareceu que não teve outra solução a não ser entregar [a filha] aos cuidados de sua madrinha, [a requerente], e que pouco tempo depois procurou a requerente para ter sua filha de volta, mas a mesma recusou-se a entregar a menor. [Maria] ainda disse que sempre procurou por notícias da menor, porém foi privada da convivência com a mesma devido à mudança de endereço da requerente, sem aviso prévio a "ré" e que tomou conhecimento da escola onde sua filha estuda e movida por um profundo desejo de voltar ver a filha foi à escola, porém foi privada de vê-la, o que a levou a "momentâneo descontrole emocional".

Vale ressaltar que, apesar de ambos os "genitores" estarem sendo objeto da propositura, a ação ruma em torno da avaliação moral de Maria e de seu desempenho como mãe, ao passo em que pouco é dito sobre Jurandir, o pai de Mariana. Até mesmo quando este é chamado a depor, aborda-se mais o desempenho de Maria como mãe do que a performance paterna. 
Notamos assim que a condução processual é organizada por uma economia moral (FASSIN, 2014) ancorada em visões sobre as relações entre os gêneros em âmbito das famílias. Ressaltamos que, em termos de condução processual, os discursos caminham no sentido de silenciar a conduta do "réu e de ressaltar uma avaliação moral da figura feminina, partindo da visão de que o cuidado dos filhos é predominantemente sua responsabilidade".

Retornando ao processo, no que diz respeito ao pleito, a equipe técnica da VIJI manifesta-se contrária ao pedido de destituição requerido por Beatriz, através de um parecer, positivando a conduta de Maria. No mesmo sentido, rumam as argumentações dos representantes do Ministério Público, através do pedido de "improcedência" da ação. Como resultado, o Juiz da Infância e da Juventude considerou que "a convivência familiar biológica melhor atende aos interesses da criança". Vale ressaltar que Mariana continua convivendo com a madrinha, por meio de visitas acordadas judicialmente.

Apesar de o argumento final do magistrado estar centrado na ideia de que o retorno à "família biológica" garantiria "o melhor interesse" de Mariana, aventamos a hipótese de o resultado não se dever exclusivamente à valorização dos laços biogenéticos (Strathern, 1995) ${ }^{15}$ como elementos fundamentais para a produção e permanência de vínculos entre pessoas e famílias. Acreditamos que, nesse caso, tão importante quanto a noção de a consanguinidade criar elos permanentes entre pais e filhos (Schneider, 1968) foi ${ }^{16}$ a ideia de a "genitora" não ter "abandonado" sua filha, mas a deixado aos cuidados da madrinha. Cremos, assim, que o "abandono", transformado em "cuidado", aproximou Maria das normas de gênero (Butler, 2014) ${ }^{17}$ em âmbito da família, favorecendo-a em termos do resultado da ação.

\subsection{Cárcere privado e afeto: "negligência" e "sofrimento psíquico"}

Joana, de acordo com os "autos", é portadora de "transtorno psiquiátrico" com manifesto "comportamento agressivo" e "delírios persecutórios". Foi denunciada por ter "exposto" Manoel, 6 anos, e Pedro, 3 anos, seus filhos e cujos pais são "desconhecidos", "à situação de abandono, grave negligência, gravíssimo risco pessoal e social e à prática de atos contrários à moral e aos bons costumes" (grifo nosso).

De acordo com a "inicial" proposta pelo Ministério Público, várias denúncias anônimas foram feitas ao Conselho Tutelar. Havia relatos de que a "acusada" os agredia, além de mantê-los em "cárcere privado", "sem alimentá-los, sem levá-los à escola e sem ensiná-los hábitos básicos de higiene". Por esse motivo, os representantes do MP consideraram tratar-se, de acordo com

\footnotetext{
15 De acordo com Marilyn Strathern (1995), as relações euroamericanas estão suportadas em uma concepção biogenética de parentesco por meio da qual há exigência simbólica de que filhos tenham dois pais "iguais em termos de doação genética, mas desiguais em termos de papéis".

16 David Schneider (1968), ao estudar o sistema de parentesco nos Estados Unidos, aborda a concomitância entre dois modos básicos de constituí-lo: como substância biogenética e como código de conduta.

17 De acordo com Judith Butler (2014), o gênero como norma atual como ideal regulador, estabelecendo fronteiras entre determinadas práticas tidas como inteligíveis, lícitas e reconhecíveis e outras consideradas ininteligíveis, ilícitas e abjetas.
} 
o art. 98, II do ECA, de situação em que os "direitos da criança e do adolescente" foram violados. Por isso, seriam necessárias medidas "protetivas" como o imediato acolhimento institucional e afastamento da mãe.

Assim foi feito e, após este acolhimento, os profissionais da Vara da Infância e da Juventude procuraram a "família extensa" de Joana, de forma a reinserir as crianças no núcleo de origem. Os meninos ficaram, portanto, sob a guarda da irmã da mãe e de uma tia materna, moradoras do mesmo terreno onde ficava a casa de Joana e de seus dois filhos.

Ao longo do processo, Joana foi sendo construída de distintas formas. De acordo com representantes do MP, a "requerida" possuía "manias de acumular objetos" e mantinha uma conduta "de desleixo em sua casa". Segundo o parecer pericial, feito pelo setor de serviço social da instituição de acolhimento para a qual as crianças foram encaminhadas, a ação de destituição de poder familiar versava sobre "uma pessoa extremamente reclusa, [que] não permite aproximação de familiares", com "transtorno psiquiátrico, embora não diagnosticado"' (grifo nosso).

Já para o setor de psicologia da Vara da Infância e da Juventude, na qual tramitou o processo, a "genitora apresenta sofrimento psíquico significativo e demanda cuidados psiquiátricos", havendo a necessidade de avaliação psicológica "para clarificação do sofrimento psíquico experienciado por ela, e das implicações deste no desempenho da função materna [...]".

A partir de depoimentos de familiares e de vizinhos, contidos no relatório do conselho tutelar e nos diversos estudos psicossociais, Joana é descrita como alguém que apresenta "ataques de fúria", sendo capaz de perseguir e atacar pessoas na rua. De acordo com uma de suas irmãs, a "denunciada" fez acompanhamento médico até os 15 anos de idade, quando a mãe faleceu, sendo, assim, interrompido o tratamento.

Nesse processo não há "interpretação qualificada" (Foucault, 2001, p.6) produzida por psiquiatra, atestando a sanidade da "acusada". Portanto, as apreciações que as testemunhas e os peritos das Varas tinham a fazer sobre o comportamento moral da acusada eram de fundamental importância para a construção do sentido de loucura e sua associação ao comportamento "negligente" materno.

Notamos que, mesmo não havendo "diagnóstico", para os diferentes integrantes do processo não paira a dúvida que se trata de uma pessoa com "transtorno psiquiátrico". À luz de ideias organizadas segundo um modelo de comportamento social (Mauss E Durkheim, 1981, p.419) e de uma moralidade sobre desempenho da função materna em nossa sociedade, Joana é vista como possuidora de comportamentos intoleráveis e perigosos para uma mãe.

Entretanto, não é apenas dessa forma que ela é categorizada. Para o setor técnico da Vara da Infância e da Juventude, na qual tramitou o processo, a "ré", apesar de "nervosa e emotiva", "é cuidadosa com os filhos e necessita acompanhamento para que consiga resolver suas demandas". Tal classificação adveio da forma como os depoentes avaliaram a acusada e como ela mesma falou de si. 
Após o acolhimento dos filhos e posterior guarda das crianças pelas irmãs e pela Tia, Joana começou a se relacionar com um companheiro, que a auxiliou na reorganização da vida. Posto que os filhos moravam no mesmo "terreno", mesmo após a medida protetiva, Joana costumava vê-los afirmando, inclusive, [.] "que cuida bem de seus filhos e que todos os dias eles vão à sua casa. Ela disse que sua casa é organizada e que quer muito reaver a guarda". Os filhos e a irmã, em mesmo sentido, ressaltaram que, apesar de Joana ser "nervosa", trata-se de uma mãe afetuosa.

À luz do que Vianna (2002) ressalta em seu trabalho sobre as dimensões tutelares da gestão da infância contemporânea, as verdades contidas em um processo envolvendo guarda, adoção e/ou destituição de poder familiar não dizem respeito exclusivamente aos objetos socialmente construídos, mas dizem respeito a objetos construtores de novas realidades. Dito de outra forma, conforme (Rinaldi, 2015), os agentes do direito envolvidos nesses processos não agem apenas disciplinando e normatizando os litigantes por meio de valores universais/dominantes.

Nesse sentido, a moralidade construída pelos envolvidos, em seus depoimentos, é capaz de afetar os rumos do processo. Acreditamos que os contornos morais criados por vítimas e acusados é parte fundamental no fluxo processual e se fazem presentes nas argumentações dos profissionais do Direito. Consideramos, ainda, que a narrativa produzida por Joana e por seus familiares possibilitou que a "ré" fosse interpretada não só como uma "boa mãe", mas como uma pessoa em "sofrimento psíquico". Sendo assim, à luz de uma economia moral (FASSIN, 2014) suportada na ideia de sofrimento, Joana pôde ser avaliada através de uma atenção compassiva, que pode vir a possibilitar-Ihe reaver os filhos, posto que o processo ainda esteja em tramitação.

\subsection{De "maus tratos" a "abandono"}

Segundo Rinaldi (2018), na Constituição Federal brasileira de 1988, assim como da Lei de Execuções penais de 1984 (LEI n 7210-1984), há previsão legal que mulheres presidiárias tenham asseguradas condições para que possam permanecer com seus filhos durante o período de amamentação ${ }^{18}$. Além da legislação citada, o Estatuto da Criança e do Adolescente, Lei 8069/1990, assim como o Código Civil de 2002 (Lei 10.406/2002), também dispõem sobre a díade presa/filhos.

Nota-se uma vasta legislação que visa assegurar às mulheres presidiárias condições para permanecer com seus filhos durante o período de amamen-

\footnotetext{
18 De acordo com Ventura, Simas e Larouzé (2015), a partir da Constituição Federal, os estados deveriam disciplinar a situação das mulheres que tem filhos em presídios, mas segundo as pesquisadoras há um baixo índice de regulações específicas. No entanto, segundo as mesmas há algumas leis infraconstitucionais que também tratam do assunto, como por exemplo a Lei 7.210/1984- Lei de execução penal (LEP A execução penal tem por objetivo efetivar as disposições da sentença ou decisão criminal) que instituiu o acompanhamento médico à mulher presa e ao filho recém-nascido (art. $\left.14 \S 3^{\circ}\right)$; a obrigatoriedade de berçário e local de amamentação até seis meses de idade (art. $83 \S 2^{\circ}$ ) A obrigatoriedade de local para gestante e parturiente, e creche para crianças maiores de seis meses e menores do que sete anos (art. 89). Vale ressaltar que a LEP sofreu alterações com a promulgação da Lei 11.942/2009 que determinou a permanência da criança com sua genitora em berçários por um período de, no mínimo, seis meses. Essa mesma lei, em seu art. 117 , inciso III e IV, abre a possiblidade de uma presa gozar benefício do regime aberto em residência particular, caso a "condenada" seja gestante ou tenha filho menor ou com deficiência física ou mental.
} 
tação, e também com o intuito que não percam o "poder familiar" pelo fato exclusivo de cumprirem pena em regime fechado.

Segundo a Lei 12.962/2014, que alterou o Estatuto de Criança e do Adolescente - 1990 está determinado no artigo $23 \S 2^{\circ}$ que "a condenação criminal do pai ou da mãe não implicará a destituição do poder familiar, exceto na hipótese de condenação por crime doloso, sujeito à pena de reclusão contra o próprio filho ou filha" ${ }^{19}$. Nessa mesma Lei, em seu artigo $19 \S 4^{\circ}$, está disposto que "será garantida a convivência da criança e do adolescente com a mãe ou o pai privado de liberdade, por meio de visitas periódicas promovidas por responsável ou, nas hipóteses de acolhimento institucional, pela entidade responsável, independente de autorização judicial".

Apesar desses dispositivos, não existe normatização nacional capaz de prescrever de que forma os estabelecimentos prisionais devem fazer valer o que neles está previsto. Segundo a Lei de execuções penais, art. $82 \S 2^{\circ}$, "os estabelecimentos penais destinados a mulheres serão dotados de berçário, onde as condenadas possam cuidar de seus filhos, inclusive amamentá-los, no mínimo, até 6 (seis) meses de idade"20.

Segundo Santa Rita (2007), como a previsão legal está dirigida aos berçários, fica a cargo das instituições a decisão sobre as diferentes formas de assegurar a permanência da díade mãe/bebê nesse cenário. Dessa maneira, há uma grande variação de atendimentos que dependem das gestões das Secretarias Estaduais de Segurança Pública. Há unidades que destinam celas para que a criança fique em companhia da mãe, enquanto algumas possuem berçários e outras contam com um espaço específico (unidade materno-infantil) para a permanência das presas e de seus filhos. As variações não se restringem às nomenclaturas e às modalidades de atendimento, mas também se manifestam quando o assunto é o tempo de permanência da criança com a mãe. De acordo com Santa Rita (2007) há instituições que garantem esse acolhimento exclusivamente durante o período da amamentação, ao passo que outras mantêm o vínculo por um ano, sendo importante mencionar as que, possuindo creches em suas instalações, garantem a conivência entre mãe e filho por até três anos.

No estado do Rio de Janeiro, existe a Unidade Materno Infantil Talavera Bruce. A UMI, embora anexa ao presídio feminino Talavera Bruce, guarda autonomia administrativa em relação àquele presídio. Apesar de não se tratar necessariamente de um presídio e ser administrado pela SEAP (Secretaria do Estado de Administração Penitenciária), faz parte de suas dependências, em Bangu, no Rio de Janeiro²1.

Trata-se de uma instituição onde as "internas" ficam com seus bebês que nasceram no sistema prisional até completarem seis meses de vida. Se19 As razões que levam à "suspensão" ou à "destituição do poder familiar" estão previstas tanto nos artigos 1637 e 1638 do Código Civil de 2002, quanto no artigo 24 do Estatuto da Criança e do Adolescente (ECA). Segundo os comentários sobre o ECA produzidos por Rossato (2012) "o art. 24 do Estatuto traz a regra de que a perda e a suspensão do poder familiar serão decretados judicialmente, em procedimento contraditório, nos casos previstos pela legislação civil, bem como na hipótese de descumprimento injustificado dos deveres e obrigações que alude o art. 22" (2012,p.170)

20 (Redação dada pela Lei n 11.942, de 2009)

21 Esta entidade é composta por um corpo técnico de profissionais (agentes penitenciárias, administração, psicólogos e assistentes sociais) vinculados a SEAP que trabalham em prol do bom funcionamento da Unidade. 
gundo Rinaldi (2018), no oitavo mês de gestação, as "internas" que estão em outras unidades prisionais do estado do Rio de Janeiro são transferidas para a Penitenciária Talavera Bruce. Após o parto, são direcionadas à UMI, onde ficam em contato integral com o filho. Após esse período, as crianças são "desligadas"22" das mães/presas e podem ter três destinos: ficar com a "família extensa" (avós maternos, paternos e tios, tanto da mãe quanto do pai), ir para as casas de acolhimento ou para "famílias acolhedoras ${ }^{23 "}$ ou, em último caso, ser encaminhadas para a adoção (após processo de DPF).

O último processo escolhido trata do destino de Pedro, um bebê nascido em contexto de tutela do sistema prisional ${ }^{24}$ descrito acima. $O$ infante foi encaminhado, junto com sua mãe Carolina, à Unidade Materno Infantil Talavera Bruce, onde ficou até os sete meses de idade. Ao longo de sua permanência na UMI foi registrado por Evandro, parceiro afetivo de Carolina.

Segundo os "autos", Carolina possuía quatro passagens pelo sistema prisional. Além de Pedro, era mãe de sete filhos, dentre os quais, dois nasceram dentro de presídios. Uma dessas crianças foi adotada; quatro estavam sob o cuidado de sua avó materna (a única referência familiar que possuía); e dois outros, sob a guarda de seu primeiro companheiro. Sendo assim, a "ré" não possuía ninguém para ser o guardião legal de Pedro, enquanto cumprisse pena. Somente seu parceiro Evandro, que ao longo do processo tornou-se "desaparecido", poderia assumir essa função.

No que diz respeito à ação em tela, de acordo com o relatório psicossocial produzido pela equipe técnica da Unidade Materno Infantil Talavera Bruce, Carolina deu entrada na UMI com seu filho e, no mesmo mês, foi comunicado ao serviço social daquela unidade "um episódio de violência contra o bebê". Segundo os "autos", a "ré" expôs o filho "a situação de risco", submetendo-o a maus tratos, "tendo sido constatado que gritava e sacudia a criança com violência para forçar o infante a comer, sob o argumento de que iria perder peso. [...]".

Após esse ocorrido, a "acusada" apresentou "problemas de disciplina". De acordo com esse relatório, à luz da orientação da juíza de direito da VIJI, foi feito o "desligamento"25" da "interna" e de seu bebê e o encaminhamento da criança para uma instituição de acolhimento infantil. Segundo a mesma

\footnotetext{
22 O "desligamento", evento crítico assim chamado pela UMI enquanto unidade, acontece de três em três meses, determinado pelo Juiz. Nesse dia, as mães e seus filhos são separados; a criança geralmente permanecerá com a guarda provisória e a mãe continuará cumprindo sua sentença de volta ao regime fechado.

23 O Programa "Família acolhedora" consiste em cadastrar famílias para receberem e acolherem em suas casas, por um determinado período, crianças ou adolescentes em situação de risco pessoal e social, representando possibilidade de continuidade da convivência familiar em ambiente sadio para a criança ou adolescente. A família assume o papel de preparar o acolhido para o retorno da família biológica ou para a adoção definitiva.

24 Ver Rinaldi (2018)

25 Segundo Rinaldi (2018), o "desligamento", termo que se refere à separação da díade mãe/bebê, é um rito legal conduzido por um/uma magistrado da área da Infância e da Juventude. Este ocorre no espaço da instituição, em presença de um representante do Ministério Público da área da infância e da Juventude, de membros da direção da Unidade, da equipe técnica (psicólogo e assistente social), da "interna", da criança e dos familiares/pretensos guardiões. É um rito de instituição (BOURDIEU, 1989) por meio do qual a/o juiz/a transfere a guarda da mãe para uma pessoa que se tornará a responsável legal pelo infante ao longo do cumprimento da pena. Além disso, é um momento de instrução legal dada pelo Juiz aos guardiões sobre o trâmite legal para a continuidade do processo de guarda.
} 
peça, Carolina afirma ter agido para evitar ser repreendida pela pediatra da UMI. Entretanto, "demonstrava não ter paciência com a criança".

Em face da "denúncia", a direção da Unidade Materno infantil acionou a Justiça da Infância e da Juventude, que optou pela "medida protetiva" de afastamento da criança de sua mãe. Uma vez que o pai de Pedro "não foi encontrado", por não possuir endereço certo, a opção tomada foi pelo acolhimento institucional.

Ao longo desse percurso, os representantes do Ministério Público do Estado do Rio de Janeiro optaram por mover uma ação de destituição de poder familiar em face de ambos os "genitores", Carolina e Evandro. Entretanto, apesar de a ação incidir sobre ambos, todo o fluxo versa sobre a "acusada", tal como vimos ocorrer em outros documentos.

Após cinco meses de acolhimento institucional do bebê, essa medida protetiva gerou feitos imprevistos. Segundo representantes do MP, Pedro passou a ser considerado "em situação de abandono", o que possibilitou seu encaminhamento para a adoção. Ao longo desse percurso, a "ré" foi deslocada do lugar de "violenta" para o de "abandonante26". Algo análogo ocorreu com Evandro, que perde o posto de "desaparecido", passando a ser um "genitor" que abandona "moral, material e afetivamente" o filho.

Em face disso, o Juiz da infância responsável em julgar o pedido de destituição de poder familiar considera:

"[...] que os genitores dos menores descumpriram dolosamente os seus deveres, não prestando minimamente a assistência material e moral necessárias. Notam-se abandono material, moral e afetivo, de modo que não se vislumbra alternativa para a preservação do melhor interesse dos menores, senão a destituição do poder familiar. Por tais razões, merece prosperar o pedido de decretação da destituição do poder familiar [...]".

No decorrer do período em que Pedro encontrava-se sob a guarda provisória de uma "família substituta", que aguardava a decisão final da ação de destituição de poder familiar para homologação da adoção, Carolina engravidou novamente. A "acusada" se encontrava ainda dentro do sistema prisional e, de acordo com o relatório psicossocial produzido pela UMI, a equipe técnica da Unidade foi orientada pelo magistrado da Infância e da Juventude a não a acolher com seu novo bebê. Tal orientação se deveu ao "histórico de maus tratos que nutria em relação ao seu filho Pedro".

Em paralelo, a Defensoria Pública em exercício no sistema penitenciário propõe um requerimento de apelação, solicitando que Carolina tenha novamente a guarda de Pedro e que sua adoção não seja deferida. Apesar do requerimento, a decisão foi pela destituição e adoção sob o argumento de que "a reintegração da criança à genitora acarretaria danos psicológicos irreversíveis, visto que a criança encontrava-se inserida em família substituta".

26 Segundo Fonseca (2012), o termo "mãe abandonante" , a depender do contexto, carrega rejeição emocional, como se a entrega do filho fosse uma escolha consciente das mães em questão. 
Supomos que a decisão final sobre a impossibilidade de Carolina continuar a ser mãe de Pedro se deva não somente ao fato de ter "sido violenta com o bebê", mas também por ela ter tido várias passagens pelo sistema prisional, somada ainda à ideia de ser "agressiva" e pouco afeita aos filhos. Esses foram os elementos que impossibilitaram sua positivação moral, afastando-a das normas do gênero feminino e de ideal de desempenho materno, contribuindo, assim, para a sentença final.

\section{Considerações finais}

No que diz respeito ao universo jurídico, à sua forma de compreensão e tratamento das ações de "destituição do poder familiar", uma questão há de ser posta: agiria o Judiciário exclusivamente de maneira discriminatória e normatizadora? Os oficiantes do Direito compreendem e tratam do exercício parental por meio de um modelo de família e de relações entre os gêneros que procurariam tornar universal?

Segundo grande parte da literatura histórico-antropológica sobre gênero, família e parentesco na esfera Jurídica, os oficiantes do Direito fazem uso de um parâmetro "ideal" para julgar os litigantes, por meio de valores que consideravam ideais. Conforme essa visão interpretativa, o Judiciário agiria definindo fronteiras para os gêneros, tomando para si definir noções de honra, sexualidade, trabalho, educação e família.

Ao longo desta pesquisa, foi possível perceber a recorrência desse padrão no Judiciário. Entretanto, pudemos observar que os oficiantes do Direito, além de estabelecerem uma ordem moral ideal por meio da qual avaliam os envolvidos nos "autos", na prática processual, são afetados pelos ideais de moralidade elaborados por vítimas, acusadas e testemunhas.

Do ponto de vista da relevância, dos efeitos e das limitações da análise esboçada nesse texto, é importante ressaltar que realizamos uma pesquisa etnográfica, cujo foco foi um pequeno número de documentos que tramitaram na comarca do Rio de Janeiro. Apesar de versar sobre uma população restrita - três ações de DPF, dentre quarenta e nove "autos" coletados - sua esfera de alcance é vasta. As análises são produtos de pesquisas qualitativas e, para essas, as escolhas amostrais da população interrogada e os critérios de "representatividade" não são o que conduzem a reflexão. Nas pesquisas documentais, com o uso do método comparativo, importam tanto as singularidades quanto os padrões gerais apreendidos nas incursões analíticas.

Sendo assim, a partir do material apresentado pudemos observar que os profissionais das Varas da Infância e da Juventude, do Ministério Público, da Defensoria Pública, os pais adotivos, os "pretendentes à adoção" e as famílias de nascimento formulam sentidos controversos em torno do que seja o exercício materno e a possibilidade de constituir família. Noções como "abandono", "cuidado", "negligência", "sofrimento psíquico", "maus tratos", "sangue", 
AÇÕES DE DESTITUIÇÃO DO PODER FAMILIAR EM PROCESSOS DE ADOÇÃO NO RIO DE JANEIRO: VALORES MORAIS E PRÁTICAS LEGAIS

"afeto" são categorias fluidas, negociadas ao longo das práticas jurídicas.

Tais reflexões levam a pensar que as formas de governo das infâncias e juventudes, no que tange ao poder familiar, não se sustentam apenas pelos "fatos legais", mas também por "sensibilidades" morais. Sendo assim, a possibilidade de permanecer ou não no lugar de mãe de pai não é algo que depende apenas do mundo das leis, mas é antes como os valores morais são acionados e negociados nas práticas jurídicas.

A opção por esse caminho interpretativo se deveu ao entendimento de que, em âmbito processual, ocorrem negociações de valores morais. Em outros termos, na construção dos "autos", uma avaliação formalizada dos envolvidos não se faz somente através de categorizações, representações sociais e avaliações morais cristalizadas, mas também por meio de negociações que se dão na própria esfera do processo. Nesse sentido, o que os litigantes têm a dizer sobre seus comportamentos pode ser transformado em valor por meio do qual serão avaliados pelos representantes da justiça.

\section{Referências}

AZAMBUJA, Maria Regina Fay de Os bebês filhos de mães que cumprem pena privativa de liberdade. Revista Gênero e Direito. V.01, p. 46-67, 2013.

BOURDIEU, Pierre O poder simbólico. São Paulo: Difel,1989.

BRASIL. Conselho Nacional de Justiça. Departamento de Monitoramento e fiscalização do Sistema carcerário e do Sistema de execução de medidas socioeducativas - DMF. Novo diagnóstico de pessoas presas no Brasil. Brasília, junho, 2014.

BRASIL. Conselho Nacional de Justiça. Poder Judiciário. Cartilha da Mulher Presa. $2^{\circ}$ Ed. 2012.

BRASIL. LEI No 12.010, DE 29 DE JULHO DE 2009. Disponível em> http://www.jusbrasil.com.br/legislacao/818490/lei12010-09>. Acesso em 5 de out. 2010

BRASIL. Lei N ${ }^{\circ}$ 12.313, de 19 de agosto de 2010. Presidência da República, Casa Civil, Subchefia para Assuntos Jurídicos. Altera a Lei n 7.210, de 11 de julho de 1984 - Lei de Execução Penal, para prever a assistência jurídica ao preso dentro do presídio e atribuir competências à Defensoria Pública.

BRASIL. Lei No 12.962, de 8 de abril de 2014. Presidência da República, Casa Civil, Subchefia para assuntos Jurídicos. Altera a Lei no 8.069, de 13 de julho de 1990 - Estatuto da Criança e do Adolescente, para assegurar a convivência da criança e do adolescente com os pais privados de liberdade.

BRASIL. Lei Nº 7.210, de 11 de julho de 1984. Institui a Lei de Execução Penal.

BRASIL. Lei N 8.069, de 13 de julho de 1990. AMPERJ Legislação. Estatuto da Criança e do Adolescente. Dispõe sobre o Estatuto da Criança e do Adolescente, e dá outras providências.

BUTLER, Judith. Regulações de Gênero. Cadernos Pagu 4, Jan- julho 2014, p.249-274.

DAS, Veena; POOLE, Deborah. El estado y sus márgenes. Etnografías comparadas. Cuadernos de Antropología Social, n. 27, p. 19-52, 2004.

ESTATUTO DA CRIANÇA E DO ADOLESCNTE E A LEGISLAÇÃO CORRELATA. Lei nº 8069/90, de 13/07/90 Atualizada e legislação correlata. Associação Brasileira dos Magistrados da Infância e da Juventude. Rio de Janeiro, 2004, p. 207.

FASSIN, Didier. Compaixão e repressão: a economia moral das políticas de imigração na França. PontoUrbe, n. 15, p. 2-22, 2014 
FONSECA, Claudia. Mães abandonantes, fragmentos de uma história silenciada. Estudos Feministas. Florianópolis 20(1): 344: jan/abril, 2012.

FONSECA, Claudia. O abandono da razão: a descolonização dos discursos sobrea infância e a família. In: Souza, André Luiz (org.) Psicanálise e colonização: leituras do sintoma social no Brasil. Porto Alegre: Artes Médicas, 1999.

FONSECA, Claudia. Quando cada caso não é um caso: pesquisa etnográfica e educação. Revista Brasileira de Educação, Rio de Janeiro, ANPEd, n. 10, jan./abr, p. 58-78, 1999.

FOUCAULT, Michel. Os anormais. Rio de Janeiro: Martins Fontes, 2001.

GUIA DO USUÁRIO. Disponível em http://www.tjpe.gov.br/coordvinf/arquivos/cartilha_cadastro_nacional_de_adocao. pdf. Acesso em: 25 maio. 2010. LEI N 12.010, DE 29 DE JULHO DE 2009. Disponível em http://www. jusbrasil.com.br/legislacao/818490/lei-12010-09. Acesso em 5 de out. 2010.

MUZZOPAPPA, Eva; VILLALTA, Carla. Los documentos como campo: reflexiones teórico-metodológicas sobre un enfoque etnográfico de archivos y documentos estatales. Revista Colombiana de Antropología, v. 47, n. 1, p. 13-42, 2011.

SANTA RITA, Rosangela. Mães e crianças atrás das grades: em questão o princípio da dignidade da pessoa humana. 2006.Dissertação (Mestrado em Política Pública)- Faculdade de Serviço Social, Universidade de Brasília. Brasília, julho.

RINALDI, Alessandra de Andrade. Laços desfeitos, vínculos construídos e "socioafetividade": um estudo sobre valores morais e práticas legais no cenário da adoção no Rio de Janeiro. IN: GOMES, Mariângela Gama de Magalhães; FALAVIGNO, Chiavelli Facenda; DA MATA, Jéssica. Questões de gênero: uma abordagem sob a ótica das Ciências Criminais. São Paulo: Editora D’Plácido, 2018.

RINALDI, Alessandra de Andrade) A sexualização do crime no Brasil: um estudo sobre criminalidade feminina em contexto de relações amorosas(1890-1940). Rio de Janeiro: FAPERJ/MAUD X.2015.

SCHUCH, Patrice. Práticas de justiça: Antropologia dos modos de governo da infância e juventude no contexto pós-Eca. Porto Alegre: Editora da UFRGS, 2009.

STRATHERN, Marilyn. Necessidade de pais, necessidade de mães. Revista Estudos Feministas, vol 3,n², p.303329, 1995.

SCHNEIDER, David. American Kinship: A cultural account. Englewood Cliffs, Prentice-Hall, 1968.

VIANNA, Adriana de Resende Barreto. Limites da menoridade: tutela, família e autoridade em julgamento. 2002.(Doutoramento em Antropologia Social) - Museu Nacional,Universidade Federal do Rio de Janeiro. 